\title{
Benefits and Pitfalls in Utilization of the Internet by Elderly People
}

\author{
Libuse Svobodova, Miloslava Cerna \\ University of Hradec Kralove, Faculty of Informatics and Management, Rokitanskeho 62, \\ Hradec Kralove, Czech Republic \\ libuse.svobodova@uhk.cz, miloslava.cerna@uhk.cz
}

\begin{abstract}
The role of advanced technologies is being discussed in public, academic and government environments. The paper deals with the current issue of computer literacy in the elderly people with focus not only on benefits but also on pitfalls connected with their use. The paper brings an insight into the technical literature review. It strives to summarize key beneficial outcomes and contrary unexpected obstacles which elderly people face when they use information and communication technology. A set of examples as practical demonstrations of real computer usage by elderly people illustrates the issue on the national scene. The research was run to explore the computer literacy in elderly people from three perspectives, roughly corresponding to three kinds of elderly people reflecting their physical and mental state. Findings from the surveys which were conducted with a group of elderly respondents in the senior homes and findings from the interview with a young lector teaching old generation show the issue in the local city environment. A question on benefits of organized course for the elderly from the questionnaire explores the survey from four perspectives and brings enriching findings. Findings from literature review correspond to findings gained from the research. Positive attributes of active utilization of the Internet contribute to active ageing, to the combat of the feelings of social isolation and loneliness.
\end{abstract}

Keywords: Benefits, Elderly People, Expectation, Pitfalls, Realization, Research.

\section{$1 \quad$ Introduction}

Population is growing old which is a general fact scientifically validated by statistics of individual countries, see statistics of the national Czech Statistical Office of the Czech Republic (CZSO) [1]. Percentage of the population classified as elderly people is steadily increasing.

Elderly people as a term doesn't have a single definition; there is no general agreement when the person is considered old. Its definition slightly varies according to the environment it is used or discussed, e.g. state economic system or sociological disciplines. Applied chronological age of 65 years in this paper stems from statement 
of the World Health Organization which is a widely recognized health expert in 150 countries within the United Nations' system.

"Most developed world countries have accepted the chronological age of 65 years as a definition of 'elderly' or older person. While this definition is somewhat arbitrary, it is many times associated with the age at which one can begin to receive pension benefits. At the moment, there is no United Nations standard numerical criterion, but the UN agreed cutoff is $60+$ years to refer to the older population. " [2]

Casado et al. [3] discuss the issue of active ageing in their recent empirical study on technology and elderly people in the research conducted with the 55 to 94 years old group of people. So, as the starting point they defined the age 55. There is no strict point defining the beginning phase of the age category called elderly people in statics and charts in sources processed in this paper that is why the inhere presented charts also work with not strictly unified beginning of the senior age.

There are two inexorably developing trends; population is ageing and new technology is constantly evolving and improving. Utilization of technology by elderly people is being a current topic, with solutions lagging behind or coming ad-hoc. It is true that there are attempts or even established a kind of tradition in training older people how to gain computer literacy, e.g. within U3A (the university of the Third Age) in the UK [4] but there is no comprehensive and functional system.

\section{$2 \quad$ Materials and methods}

The aim of the paper is to analyse the current computer literacy in elderly people with a focus on benefits and possible difficulties and pitfalls which go along with utilization of computers and the Internet.

The research procedure consisted of the following phases:

- The first phase dealt with the introduction to the topic and defining the key term 'elderly people'.

- Methodological frame encompassed goal setting, description of the study procedure and literature review.

- Literature review consists of two sections. The first one brings the results from official statistical recordings' so that via this way the width of the issue is visualized and serves as a starting point to the insight into the later main section dealing with benefits and pitfalls in utilization of ICT elderly people.

- In the next phase the issue of computer literacy in elderly people on the local scene was discussed based on the real programmes which had been organized for the elderly people and on the outcomes which were consequently published. This phase forms a kind of a balance to the 'cold' statistical data and 'remote' academic studies as it focuses on real tangible events in the local circumstances. Due to the fact that during the work in the field which means in the home for elderly people or in the course of computer literacy for retired people organized by the Municipality of the regional city, it was instantly revealed that the utilization of social network is too narrow topic, mostly neglected by the accessible sample. The perspective of benefits and pitfalls got extended to the wider topic to the computer literacy. 
- Following stage deals with processing and publishing results and findings from the survey. The survey was conducted in November and December 2016 in 12 primary schools which have been engaged in the long-term "intergeneration" project "Internet for Senior Citizens" with the Municipality of Hradec Kralove in organizing courses of computer literacy for the elderly.

Primary and secondary sources were used. As for secondary sources, they comprised websites of selected surveys and also official statistics from the Czech Statistical Office and Eurostat, technical literature, information gathered from professional journals, discussions or participation at professional seminars or conferences. Then it was necessary to select, categorize and update available relevant information from the collected published material.

Work in the field followed: elderly people were contacted both in their senior homes and at home with home care, then appointments and one interview with a young lecturer participating in the training course for the elderly people were done.

Data from the project "Internet for the Senior Citizens" were gained from discussions, interviews, questionnaires and from the Presentation at the graceful closing ceremony where participants of the courses were awarded with diplomas. In total 173 senior citizens graduated in the last term - they successfully completed one of three kinds of courses: Internet for beginners, Internet for advanced and Digital photography course. Researchers distributed questionnaires to the Elderly participants "Students", to primary school pupils - "Lecturers", to primary school teachers who ensured smooth run in each course - "Tutors" and to the Directors of project involved schools. Researchers gained filled in questionnaires from all directors, from 15 teachers - "Tutors", 99 pupils -"Lecturers", and 82 senior citizens - "Students". It means that nearly half of "Students" provided researchers with the valuable response.

\subsection{Literature review - utilization of telephones, computers and the Internet by elderly people}

In spite of the fact that advanced technologies are in the Czech Republic commonly used for communication, in case of the analysed category of elderly people telephones are commonly used but as for utilization of computers and the Internet they are used to much lesser extent, see Fig.1. Data are collected from the national Czech Statistical Office and Eurostat. The graph in Figure 1 shows that the Internet use is very closely related to the computer use.

In the use of computers and their services to communicate with other people we still don't achieve or even do not come close to the level of their utilization as is the average of the EU 28 [6], it is necessary to clarify that the data referring to pure communication reasons aren't available for elderly people, the data in this case refer to $16+[7]$.

When it comes to utilization of the Internet by the group 65+ (elderly people) in the United States there were 58\% users but in comparison with the Czech Republic the number was just half, only $28.4 \%$. It is interesting to follow the time-line and the 
trends; in $200528 \%$ of elderly people used the Internet in the United States but as for the Czech Republic, there were only $2.2 \%$ of $65+$ people using the Internet.

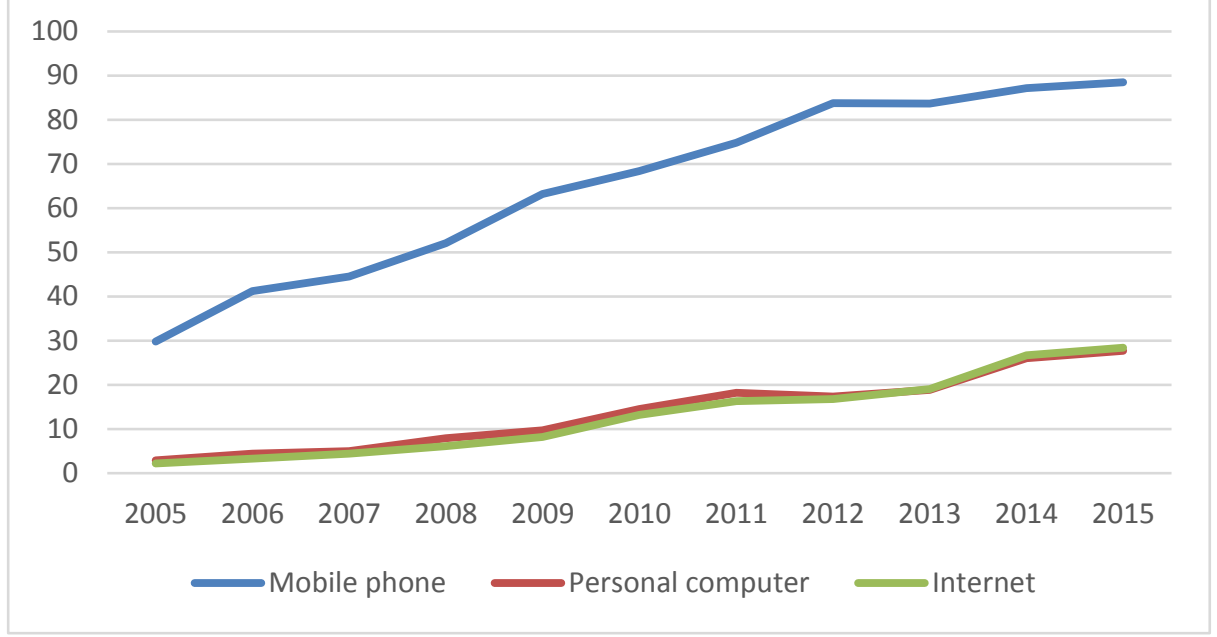

Fig. 1. Individuals aged $65+$ years old that use information and communication technology in the Czech Republic. Data are given in percentages. Source: [5]

In 2010 , the Internet was used in the States by $43 \%$ of elderly people but in the Czech Republic there was an incredible six fold increase in users meaning that $13.2 \%$ $65+$ people were using the Internet. Five years later in 2015 the rise wasn't as steep as in previous years, but the number of Czech elderly users doubled and reached $28.4 \%$, in the States more than half of the elderly people to be precise $58 \%$ use the Internet.

The increase in Internet users in connection with the development and expansion of advanced technology is evident. Its share may have seniors who have become seniors in recent years and got into contact with information and communication technology e.g. in their work, which for the previous older generation was not very common.

\subsection{Literature review - benefits and pitfalls}

The other part of the literature review deals with the key issue of the paper; it focuses on computer literacy in the elderly people, on the aspects of benefits and pitfalls of ICT utilization, especially of the Internet and media.

The pros and contras, positives and negatives of Internet utilization are widely discussed in the academic sphere. But as for the age category of 'elderly people' the offer of academic studies gets narrower, selected studies follow.

Chen, Schultz [8] discussed in their review study beside other topics the issue of social isolation in the use of social networks by elderly people. Evidence indicates that contemporary information and communication technologies (ICT) have the potential to prevent or reduce the social isolation of elderly people via various mecha- 
nisms. The findings of this review suggest that the elderly can benefit from ICT interventions and will use them (sometimes frequently) after proper training.

Gonzalez [9] work deals with main habits when new technologies are used by older people. The level of knowledge and their level of education are highlighted. The purpose was to analyse whether the technological skills of elderly people are sufficient, as well as to know if the audio-visual resources are appropriate. This study strives to find out if the ageing society is prepared to handle everything the Internet has to offer. This study took place in three countries of the European Union: the United Kingdom, France and Spain. The worst results were found in Spain. In 2013 and 2014 the Internet was used by one third of elderly people (33\%). Nearly the same number about one fifth of the elderly people used tablet pc (21\%), WhatsApp (20\%) and Facebook (19\%). Mobile phone is used by $81 \%$. As for social networks, $85 \%$ of Spanish elderly people stated they had never participated, $14 \%$ participated from time to time and only $1 \%$ claimed that they participated online regularly.

The other presented study comes also from Spain. Montaa [10] claims that Spanish elderly people show considerable interest in the Internet and more than $60 \%$ of them check their email daily. Their use of the Internet, however, is eminently pragmatic, so they tend not to explore and use its potential as social media, as means of social communication.

Active Ageing is a term which accompanies the elderly people theme in academic papers as well as in texts written for the general public. Llorente-Barroso [11] explores active ageing in elderly people within the research on utilization of the Internet and its potential. Global ageing has led European and international organizations to develop programs for active ageing, in order to reconstruct the role of the elderly in society. Active ageing includes social communication aspects which have been the subject of less research than other more pressing ones linked to physical and economic characteristics. The results of the qualitative content analysis of discussion indicate that the Internet is a source of opportunities for the elderly, and this potential may be divided into four categories: Information, communication, transactions and administration, together with leisure and entertainment. This potential improves the quality of life for the elderly and contributes to their active ageing. However, to maximize this, e-inclusion programs and methodologies are needed to make the Internet userfriendlier for the elderly and provide them with training in digital skills.

Casado-Munoz [3] conducted a research with 419 people aged between 55 and astonishing 94 who participated in the "Inter-university Programs of Experiences" from the University of Burgos ) The Internet served as the platform which increases ways of communication, enables to avoid isolation and loneliness via active ageing.

Williams [12] also highlight attributes of the elderly age like loneliness and social isolation. Feelings of loneliness and social isolation can occur in many older adults and impairments that may occur in old age, such as reduced mobility, deteriorating sight, and deteriorating hearing, can prevent elderly adults from visiting their friends and family. Interpersonal communication software such as Facebook Messenger and Skype - can be very useful in keeping bonds with loved ones strong over long distances. However, sometimes these applications can be confusing and difficult for elderly people to use. A design created with considerations for the variety of abilities 
and older user might prompt more elderly users to use interpersonal communication software, and assist in the fight to reduce loneliness and social isolation in older adults.

\section{Computer literacy in elderly people on the local scene - awareness, courses and instant outcomes from research}

In the original plan there was an intention to explore utilization of social network by elderly people: what programmes and courses were offered to this age group by local authorities, by senior homes, senior center and Home Charity care service in the regional city. But there was rather limited or no awareness of the social networks among the elderly. The research had to be adapted to exploration of the computer literacy in elderly people from three perspectives, roughly corresponding to three kinds of elderly people reflecting their physical and mental state:

- Programmes and courses organized by local authorities for retired people.

- Possession of ICT devices and use of information and communication technology by people staying in the senior homes in the city.

- Home health care service and Home Charity care service in the regional city

The first group represented independent mobile retired or semiretired people who were able to move and come to the place where the course was supposed to be organized which is mostly in some city primary school. The second group was formed by the people who were of the older age category who lived in a senior home where service corresponding to their specific needs was provided who practically didn't leave the premises of the walls very often. The last group was represented by the most disabled people who were dependent on assistance of other people.

\subsection{Latest findings from the local scene}

There has been a long ten years long commendable tradition in the city of Hradec Králové. Its municipality regularly organizes free courses on computer literacy for elderly people. The awareness of this event got established among the city population due to systematic promotion on the websites of the city in the section designed for the elderly people [13] and in reports in local media [14]. Deputy Mayor responsible for education and social area stated" ... we can truly say that it is meaningful activity and brings a lot of good fruit. It is run in the spirit of intergenerational dialogue, but also improves the quality of life of our seniors. Contributes to their activation and prevents social isolation" [15]. Twelve city primary schools are currently involved into the project 'The Internet for seniors'. Pupils from the lower secondary schools teach elderly people how to work with the computer in a ten-week course one hour weekly. The teacher emphasises the value of communication between two generations, she enjoys watching how 'her' pupils cope with their new role. She has sober expectations in the progress in computer literacy in the elderly people. She states that there is no possible generalization in the technical achievements, because participants of the 
course differ. But several times she has mentioned that pupils change in perceiving the computer - from predominantly useful thing for gaming to useful device of everyday use (organizing files, searching for information, e-mails. internet banking, etc.)

Current state in selected senior or nursing homes and opportunities for improvement follow. People in three nursing homes in Hradec Králové which provide home to 2 hundred elderly people were interviewed and contacted. In nursing homes there is no special ICT equipment provided; no free ICT devices, no organized courses or ICT support. Few residents own a computer or tablet, but it is rather exceptional. Thus, people usually do not use computers. They like the situation as it is, people are satisfied, and the expert care is provided to them, they somehow do not need to search for information, explore or communicate with the outer world or study. Personal communication with people in the senior house or telephone call with the family they find satisfactory.

In case that caregivers visit of their elderly clients in their homes, the situation in the use of computers significantly differs. People tend to live a more active life and communicate more with others, if health state allows. Another criterion may be age. Computers are usually used to view photos of the family. The Internet is used by not very big deal of elderly people, and social networks even smaller. As for Home Charity care service in the regional city, it presents itself on the Internet on their modest websites [16]. Home Charity Care service helps people care for themselves and for their own household when they already cannot cope with the situation. Home Charity assists in a wide range of services but all are linked to physical or mental assistance in a serious health state, no motivating activities relating to active ageing are presented.

\subsection{Findings from the Internet for senior citizens survey}

The issue of computer literacy explored from four perspectives. There are four groups of people who participate in the project who differ in cognitive and affective areas, they differ in knowledge and experience, and they differ in interest and expectations. Four kinds of modified questionnaires were created. Some questions were same. One of these will be analysed in this paper not only that it forms one of the pillars of the paper but because all stakeholders can learn from comparison of these findings. The discussed question: In your opinion 'What benefits arise to the seniors from attending the course? Results from all four groups follow in fig. 2 and fig. 3.

Findings are worth further discussion as they vary in groups.

Most positive responses were gained from teachers who coordinate the individual courses. They are responsible for administration of the course and provide assistance to the attendees and to pupils if is needed. They expected that the positive outcomes will be very high.

Then there were Directors of schools and pupils-lecturers who were also very positive about the benefits arising to attendees of the course.

The least positive were the attendees - senior citizens about potential benefits. 


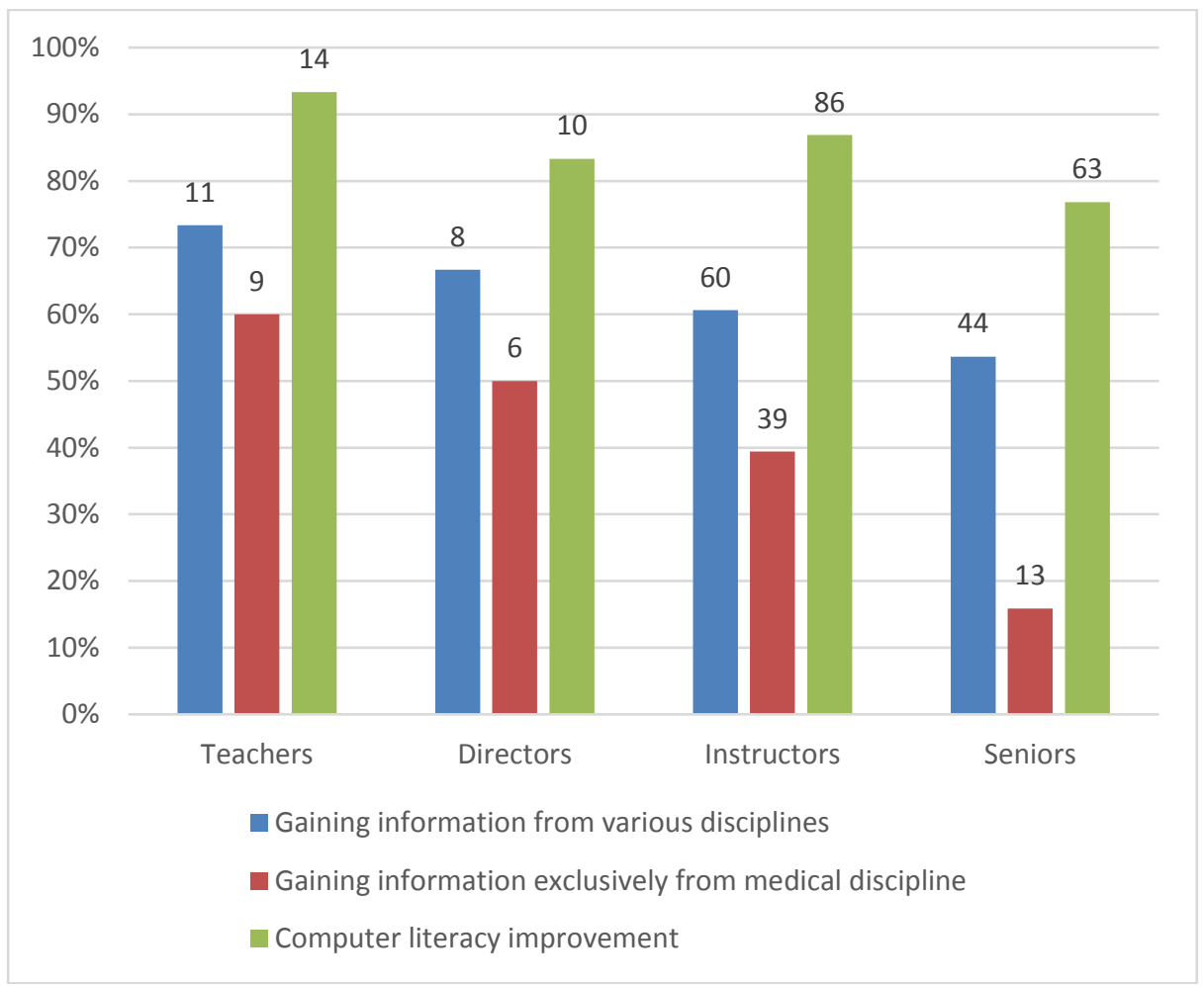

Fig. 2. Benefits - computer literacy skills

Teachers expressed greatest expectations in computer literacy skills. 14 teachers out of 15 believed in improvement of attendees' computer literacy. 13 teachers stressed potential positives to the attendees which were related to social and socializing sphere: development of other ways of communication with family. 12 teachers mentioned 'advanced' skills which relate to uploading and downloading videos and photos. Teachers expressed that there was no interest in gaining information from various disciplines, no interest in medical science. Interest in medicine was very low in analysed groups: 6 directors out of 12 expected interest in medicine discipline in the attendees, 39 lecturers out of 99 but as for seniors only 13 out of 82 had found it beneficial.

Directors could see the biggest benefits in improvement of computer literacy and meeting other people with similar interests. Other positive expectations follow: other ways of communication with family, gaining information from various disciplines, sharing and uploading photos.

Lecturers had the greatest expectations in improvement if computer literacy, opportunities to develop further communication with the family, sharing and uploading photos, gaining information from various disciplines and meeting people with similar interests. These expectations were formulated by 50 out of 99 lecturers. 
Senior attendees (63 out of 82) stated that most important area is improvement of computer skills.

Other frequently ticked options were: gaining information from a variety of disciplines, an opportunity to develop new ways to communication with family and sharing information. One third of them marked the option meeting other people with similar interests. The lowest interest is in the already mentioned category - Getting information from the medical field.

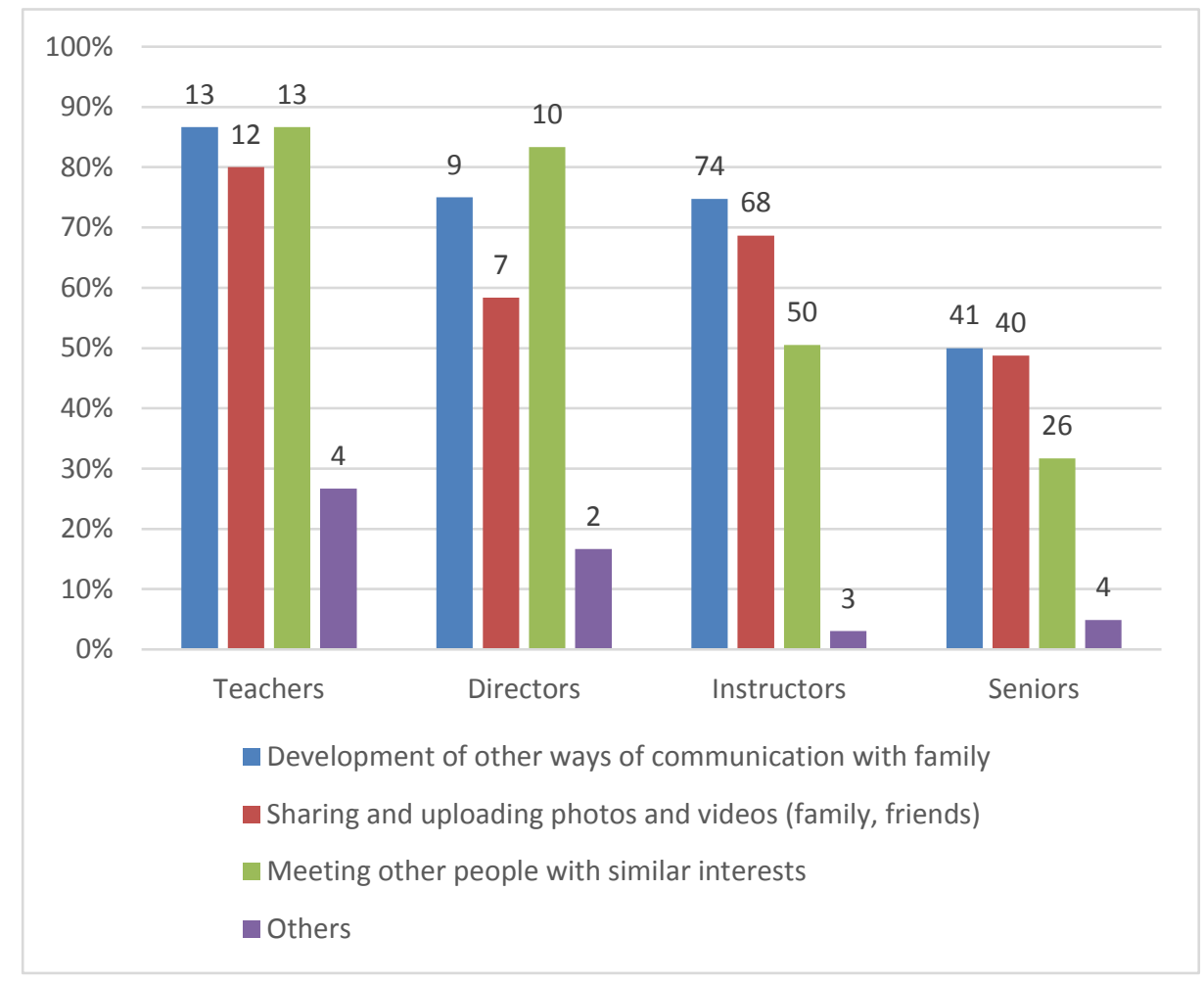

Fig. 3. Benefits - social perspective

\subsection{Findings from the international studies}

Study from the France, United Kingdom and Spain research [9] presented more fields such as owned and used technologies, sources of information, skills of elderly people, participation of social networks etc. In our here presented research we focus on two selected parts - why the elderly people use advanced technologies and whether and how they improve their ICT skills. 


\section{France}

Elderly people in France mainly use the devices to keep being informed (29\%) and connected to their families by sharing photos and videos with them (14\%). Entertainment is another one of the reasons they include to explain their use (13\%). Adapting to new technologies is considered a trend and a tendency that the elderly in France are actively participating in. the results of the survey in France highlight that most $(66 \%$ of those surveyed) are self-learners in relation to learning and improving their knowledge of ICT. Therefore, older users are willing to adapt and improve their knowledge in this field. The platform that they most commonly use to improve their knowledge is with tutorial videos. The mobile applications are also appealing to them but they only use them for personal leisure.

\section{United Kingdom}

There is a high level of interest to learn and improve in this field, especially because most British people are aware of their needs, their surroundings and the potential of new technologies to improve their living conditions. The need to feel independent is the main incentive for this increase in using and consuming technology in the UK. That is the reason we understand that for the 55 to 65 age group, studying is the main use of ICT (54\%). On the contrary, in people over 65 , the main use is still the need to keep being informed (24\%) and entertainment (22\%). Moreover and as is the case in France, despite the high interest and degree of adaptation of this profile with ICT, most of those surveyed are self-learners (69\%) or learn through the help of a family member (22\%), with tutorials being the most used platform for self-learning amongst those between the ages of 55 and $65(72 \%)$. In the Great Britain there are ICT training courses for this audience.

\section{Spain}

The Spanish mainly use this device to keep being informed and to keep in touch $(69 \%)$, for entertainment $(18 \%)$ and to talk $(10 \%)$. Only $2 \%$ claimed to have used it for education or training. This is a result that contrasts with the data obtained in France and in the United Kingdom, since we observe that in Spain there is not high adaptation to new technologies and the elderly are unaware of the actual possibilities. The elderly in Spain primarily learn about new technologies from family members and friends $(61 \%)$ followed by self-learning (26\%) and only $13 \%$ have attended a course as a way of learning about new technologies. On the contrary, Spaniards are very interested in learning about new technologies (87\% want training and only $13 \%$ don't) through classroom courses $(62 \%)$ and specific conferences about this subject and in accordance with their needs $(38 \%)$.

\section{Conclusion and Discussion}

Creation of suitable conditions for elderly people could be the proper way to finding solution for greater use of advanced technology, the internet, social networks, etc. As 
an inspiring and promising example of this approach the case study from Spain might serve. [11] The authors claim that although the Spanish elderly people are equipped with new technologies, they aren't able to use them to full extent they use only fragment of offered options and possibilities.

Elderly people in the Czech Republic widely use mobile phones but when it comes to computers, the Internet or even social network the percentage of active users is small. The surprising finding comes from senior homes in which elderly people use advanced technologies only scarcely with any need to activate themselves in further studies or adventurous exploration in the on-line communication raised the question how to motivate them. In comparison to them there are people who are even less mobile who need care assistance but still stay in their homes are much more active. The situation in senior houses might be improved via improvement in facilities, creation of centers where seniors could meet and work with technology. Hand in hand with these improvements goes the need to create enough opportunities for education in this area.

Results of the questionnaire investigation which was done by the authors of the paper are presented. Researchers applied a collaborative approach; they explored the argued project "Internet for Senior citizens" as it was a kind of orchestra where participants have specific roles; in this case those were attendees, lecturers, teachers and directors. All of them had to participate, all of them had their experience as well as expectations and all of them were after the same goal. For the successful run of the project it is not only desirable but definitely it necessary to collaborate, discuss the problems, needs, achievements and expectations within the community of stakeholders. As it was found out, expectations and belief differ; individual people perceive things differently, with different intensity. Most positive responses on the benefits were gained from teachers who coordinate the individual courses. Then there were Directors of schools and pupils-lecturers who were also very positive about the benefits arising to attendees of the course. The least positive were the attendees - senior citizens about potential benefits.

As findings show the most beneficial is when several missions combine like learning and socializing which was clearly illustrated in the case of organized computer courses where young and old generations met, gained and shared information and experience.

The following work might focus an analyzing the gained data from another perspective, for example, based on the methodology of [17].

\section{Acknowledgement}

This paper is supported by specific project No. 2103/2017 "Investment evaluation within concept Industry 4.0" at Faculty of Informatics and Management, University of Hradec Kralove, Czech Republic. We would like to thank student Marta Martinova for cooperation in the processing of the article.

\section{References}

1. Age structure, https://www.czso.cz/csu/czso/animated-life-pyramids 
2. Health statistics and information systems, Definition of an older or elderly person. http://www.who.int/healthinfo/survey/ageingdefnolder/en/, last accessed 2017/04/10

3. Casado-Munoz R, Lezcano F, Rodriguez-Conde MJ (2015) Active Ageing and Access to Technology: An Evolving Empirical Study. Comunicar. 45, pp 37-46.

4. The University of Third Age. http://www.u3a.org.uk/, last accessed 2017/04/10

5. Czech statistical office. Information Society in Figures. https://www.czso.cz/csu/czso/information_society_in_figures

6. Americans' Internet Access: 2000-2015. http://www.pewinternet.org/2015/06/26/americans-internet-access-2000-2015/

7. Eurostat, http://ec.europa.eu/eurostat/statistics explained/index.php/Digital_economy_and_society_statistics_-_households_and_individuals

8. Chen YRR, Schulz PJ (2016) The Effect of Information Communication Technology Interventions on Reducing Social Isolation in the Elderly: A Systematic Review. Journal of medical internet research. 18(1).

9. Gonzalez-Onate C, Fanjul-Peyro C, Cabezuelo-Lorenzo F (2015) Use, Consumption and Knowledge of New Technologies by Elderly People in France, United Kingdom and Spain. Comunicar. 45, pp 19-27.

10. Montaa M, Estanyol E, Lalueza F (2015) Our seniors' challenge to the new media: uses and opinions. Profesional de le Informacion. 24(6), pp 759-765.

11. Llorente-Barroso C, Vinaras-Abad M, Sancher-Valle M (2015) Internet and the Elderly: Enhancing Active Ageing. Comunicar. 45, pp 29-36.

12. Williams D, Ahamed SI, Chu W (2014) Designing Interpersonal Communication Software for the Abilities of Elderly Users. In: 38th Annual IEEE International Computer Software and Applications Conference (COMPSAC), Sweden. pp 282-287.

13. Autumn Internet courses for seniors - seniorhk.cz. http://www.hradeckralove.org/urad/internet-pro-seniory

14. Pupils in the role of real teachers, http://www.hradeckralove.org/noviny-a-novinky/zaci-vroli-opravdovych-lektoru

15. Pupils in the role of real teachers. They teaches seniors how to use the Internet, http://www.maclova.cz/aktualne/aktuality/2013/zaci-v-roli-opravdovych-lektoru-uciseniory-jak-s

16. Domestic charity care service. http://www.charitahk.cz/nase-strediska/charitnipecovatelska-sluzba/

17. Khatwani G, Anand, O \& Kar A.K (2015) Evaluating Internet Information Search Channels using Hybrid MCDM technique, LNCS, vol. 8947, pp 123-133. 